\title{
Hypercalcaemia induced psychosis due to primary hyperparathyroidism in pregnancy
}

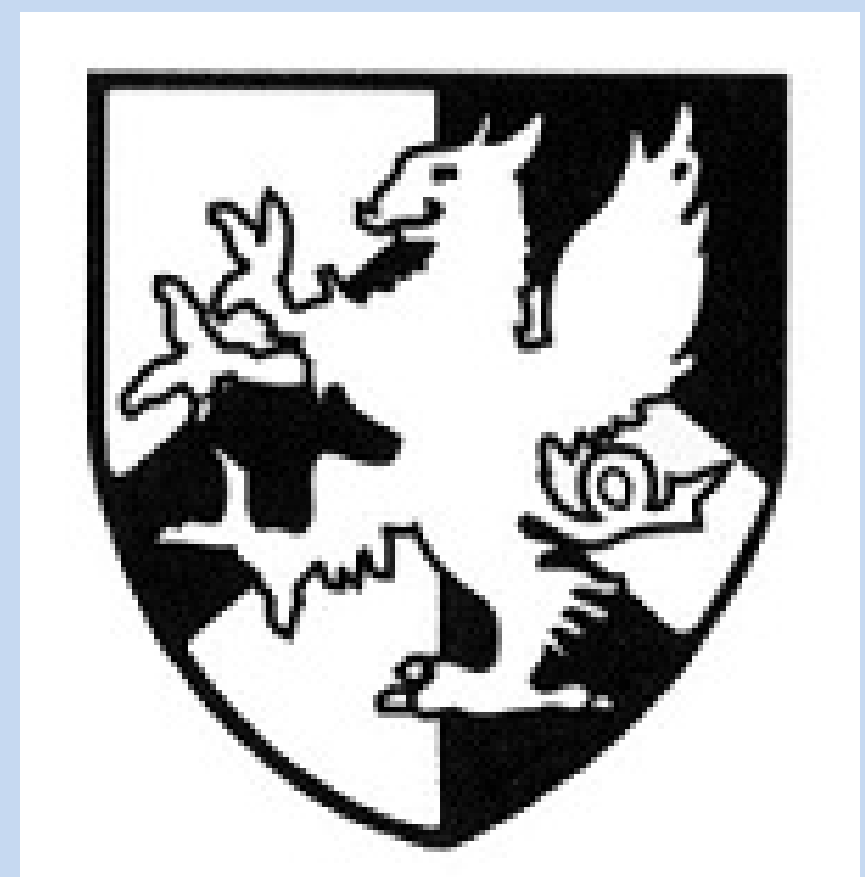

\author{
Thomas A*, Gunganah K*, Rayanagoudar G, Williams E, Hanson P, Drake WM, \\ Berney D, Parvanta L, Kirwin S, Metcalfe K \\ Department of Endocrinology, Newham University Hospital, Barts Health NHS \\ Trust, London, UK \\ *Joint first author
}

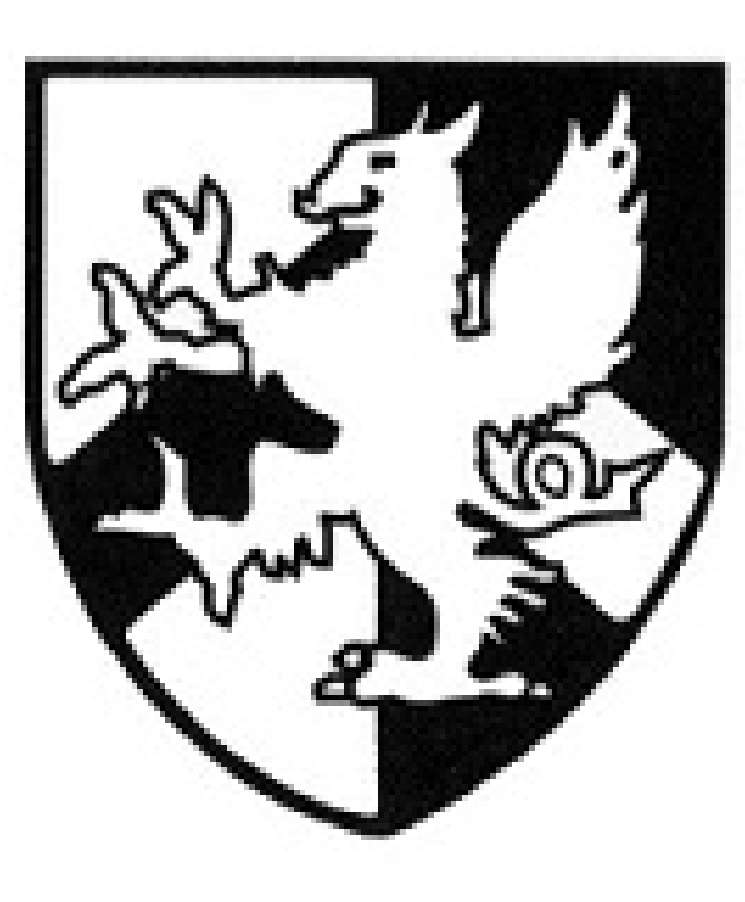

\section{Background:}

Primary hyperparathyroidism is the third most common endocrine condition in pregnancy after thyroid disease and diabetes. Untreated hypercalcaemia due to primary hyperparathyroidism increases the risk of miscarriage, intrauterine death and preterm labour. Pharmacological and surgical limitations in pregnancy often make diagnosing and managing this condition challenging. We report a complex case of hypercalcaemia-induced -psychosis due to primary hyperparathyroidism in pregnancy.

\section{Case:}

A 32-year-old pregnant lady presented at 8 weeks gestation with nausea and vomiting. She was initially diagnosed with hyperemesis gravidarum and was treated with intravenous fluids. She was incidentally found to have an elevated calcium level of $3.12 \mathrm{mmol} / \mathrm{L}$. Primary hyperparathyroidism was confirmed biochemically (Calcium $3.12 \mathrm{mmo} / \mathrm{L}$, Phosphate $0.6 \mathrm{mmol} / \mathrm{L}$, PTH post Vitamin D replacement $14.6 \mathrm{mmo} / \mathrm{L}$ (1.6 to 6.9), Urine calcium excretion index> 0.01). An US parathyroid showed a $3.7 \mathrm{~cm}$ parathyroid adenoma inferior to the left lobe of the thyroid and foetal US scan confirmed a viable pregnancy.

Her hypercalcaemia remained refractory to aggressive fluid replacement. A trial of Cinacalcet was successful in improving her calcium levels but was discontinued due to adverse reactions including worsening nausea and generalised myalgia. Throughout the first trimester, her calcium level remained above $3.0 \mathrm{mmol} / \mathrm{L}$.

At 13 weeks gestation, she became anxious, confused and developed a thought block. Our psychiatry team diagnosed her with hypercalcaemia-induced-psychosis. She was started on Olanzapine with subsequent improvement in her symptoms. Once in the second trimester, at 18 weeks gestation, she had a successful and uneventful parathyroidectomy. Post-operatively, her calcium level normalised $(2.43 \mathrm{mmol} / \mathrm{L})$ and her mental health improved with resolution of thought disorder and return to a euthymic mood. Her Olanzapine dose was halved and then weaned off. She is currently off treatment.

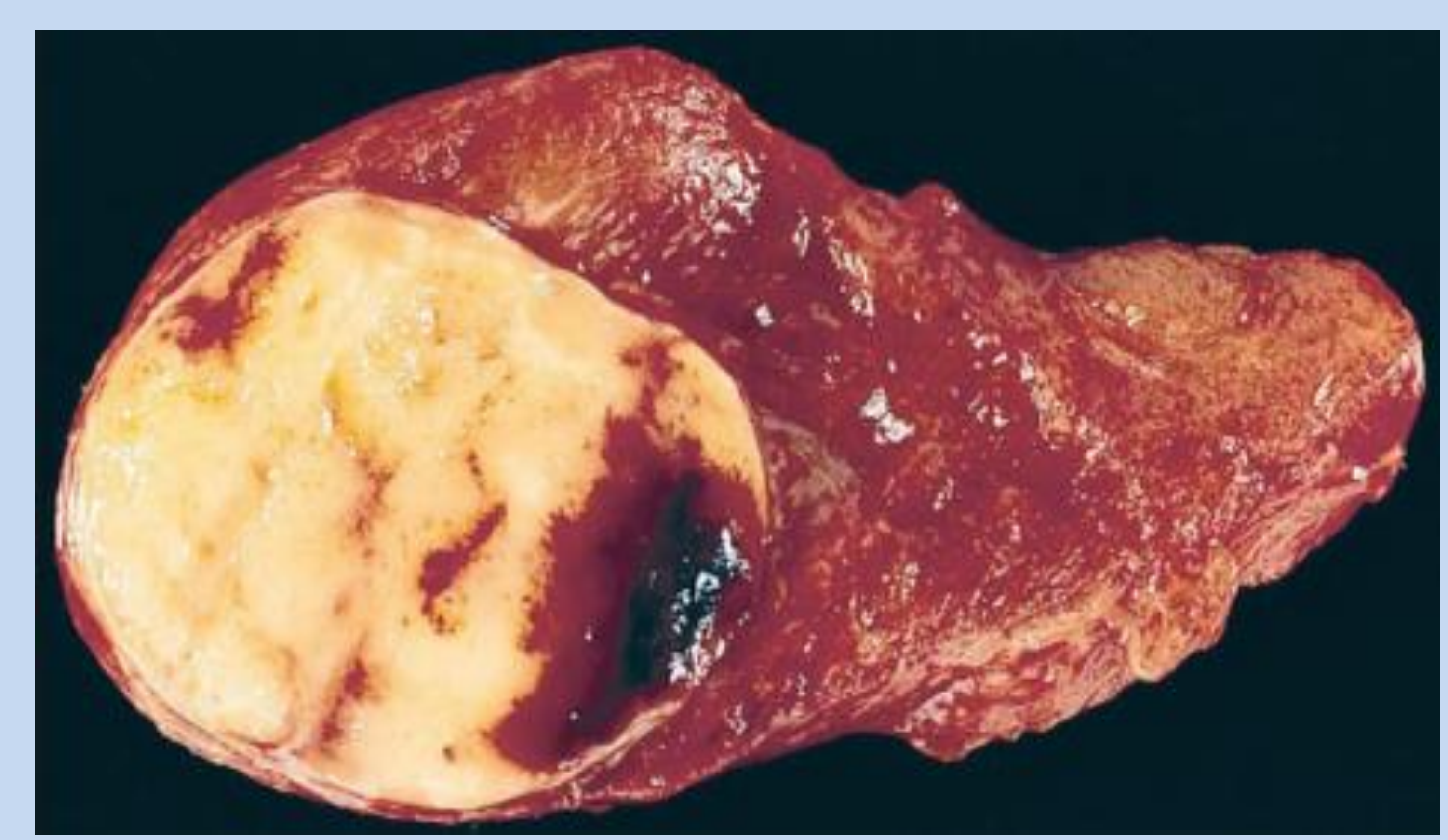

Fig 1 (left): 3Macroscopic appearance of parathyroid adenoma (Contributed by Dr. Mark R. Wick. 2014 Creative commons www.pathologyoutlines.com)

Fig 2 (Right): Histology of parathyroid ademona. (Creative commons:

https://commons.wikimedia.org/wik//File\%3AParathyroid_a denoma_histopathology_(3).jpg)

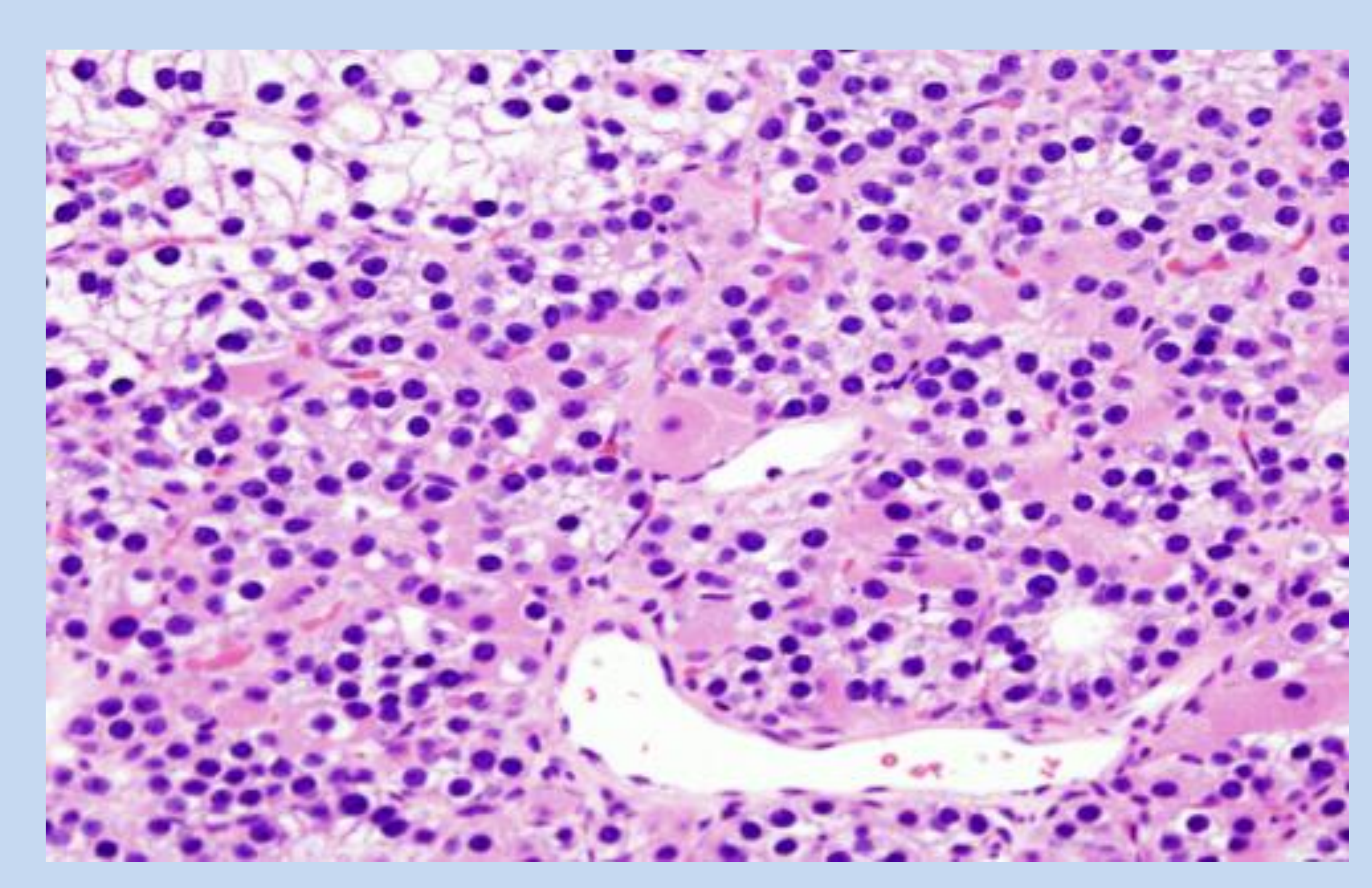

\section{Conclusion:}

This is a case of hypercalcaemia-induced-psychosis due to primary hyperparathyroidism in pregnancy successfully treated with parathyroidectomy in the third trimester. Our patient is currently in her third trimester, remains normocalcaemic and has satisfactory follow-up foetal growth scans. She is due to deliver in the next week. 